\title{
Monthly Rainfall-Runoff Modeling for Sondur Reservoir
}

\author{
Shashi Kant Jaiswal \\ Department of Civil Engineering \\ Bhilai Institute of Technology, \\ Durg (C.G.), 491001 \\ India. \\ E-mail: sk.jaiswal@bitdurg.ac.in
}

\begin{abstract}
This study presents the application of Artificial Neural Network (ANN) to modeling the rainfall-inflow relationship for Sondur Reservoir located in Chhattisgarh State of India. ANNs are usually assumed to be powerful tools for nonlinear mapping in various applications. ANN is superior to linear regression procedure used for rainfallinflow modeling. For model development twenty nine years data of monthly rainfall and inflow have been used. The results extracted from study indicated that the ANN model is efficient for rainfall-inflow modeling.
\end{abstract}

Key words - Rainfall-inflow, ANN, Sondur Reservoir, India.

\section{Introduction}

Rapid population growth and fast growing industrialization is under increasing threat of water demands. It is therefore, very important to estimate, conserve and manage water available in hydrological system to meet the future needs of water. Rainfall-inflow models play an important role in water resources management and planning. Rainfall-inflow models generally fall into three broad categories, namely black box or system theoretical models, conceptual models and physically based models. Black box model normally contain no physically-based input and output transfer functions and therefore are considered to be purely empirical models. ANN is considered as Black box model. There has been a tremendous growth in the interest of application of ANNs in rainfall-inflow modeling in 1990s. ANNs are particularly useful as pattern-recognition tools for generalization of input-output relationships. The most common applications of ANNs in water resources include those for rainfall-runoff relationships and stream flow forecasting. Dawson and Wilby [1] discussed the application of ANN to flow forecasting in two floodprone catchments in England. Jain et al. [2] applied ANN for reservoir inflow prediction and operation for Upper Indravati multipurpose project in India. Tokar and Johnson [3] developed ANN to forecast daily runoff as a function of daily precipitation, temperature, and snowmelt for a watershed in Maryland. The ASCE Task Committee [4] summarized application of ANN to solution of many hydrological problems. Tokar and Markus [5] applied ANN to predict monthly stream flow for the Fraser River Watershed in Colorado. Rajurkar et al. [6] applied ANN for modeling daily flow during monsoon flood event for a large size catchment in India. Tayfur and Singh [7] applied ANN for prediction of event based overland flow discharge due to rainfall. An application of ANN was presented by Karim [8] for modeling the rainfall-runoff relationship in a catchment area located in a semiarid region of Iran.

The net quantity of water which is available in reservoir after all losses has taken place in a given time period has been conceptualized and defined as Net-inflow (Verma ) [9]. Hence in place of inflow, net-inflow has been used to develop rainfall- inflow model.

\section{Sondur Reservoir}

Sondur Reservoir is one of the reservoirs of Mahanadi Reservoir Project Complex (MRP Complex). It is located in Chhattisgarh State of India. Sondur Reservoir is situated in Pairi basin and is built on Sondur river. The catchment area of Sondur Reservoir is 512 square kilometer. Sondur Reservoir feed water to Dudhawa Reservoir through an interbasin link canal as well as it irrigates command area. Through Dudhawa reservoir water is supplied to Ravishankar Sagar Reservoir for drinking, Industrial use, and for irrigation. The Index Map of MRP complex and location of Sondur Reservoir has been shown in Figure 1. 


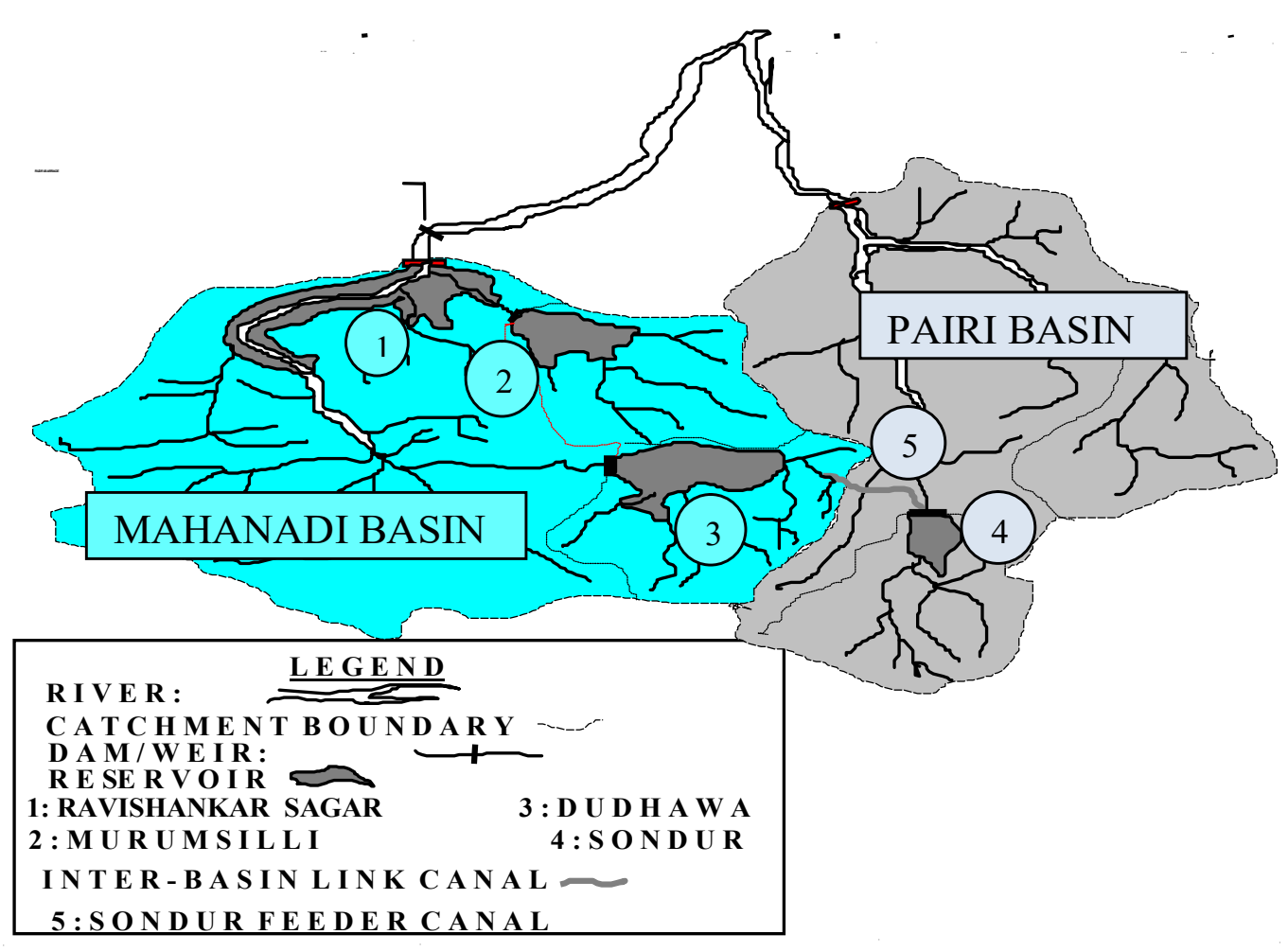

Fig. 1: Index Map of Mahanadi Reservoir Project (MRP) complex.

\section{Overview of Artificial Neural Network (ANN)}

Neural network, in general, is a highly interconnected network of a large number of processing elements called neurons in an architecture inspired by the human brain. Neural networks exhibit characteristics such as mapping capabilities or pattern association, generalization, robustness, fault tolerance, and parallel high speed information processing. Neural networks learn by examples. They can therefore be trained with known examples of a problem to acquire knowledge about it. Once appropriately trained, the network can be put to effective use in solving unknown or untrained instances of the problem. It is the learning capabilities of neural networks, which set them apart from other mathematically, formulated methods, and allows the development of neural network based methods for certain mathematically intractable problems. In this study, the training of ANNs was accomplished by a back-propagation algorithm. Back-propagation is the most commonly used supervised training algorithm in the multiplayer feed-forward networks.

An ANN is an information-processing system composed of many nonlinear and densely interconnected processing elements or neurons. Neurons in an ANN are arranged in groups called layers or slabs. Each neuron in a layer operates in logical parallelism. Information is transmitted from one layer to others in serial operations. A network can be composed of one to many layers. The basic structure of a network usually consists of three layers: the input layer, where the data are introduced to the network; the hidden layer or layers, where data are processed; and the output layer, where the results for given inputs are produced (see Fig. 1). In this study, the training of ANNs was accomplished by a back-propagation algorithm. With the development of a back-propagation algorithm, the network weights are modified by minimizing the error between a target and computed outputs. In back-propagation networks, the information is processed in the forward direction from the input layer to the hidden layer(s), and then to the output layer. The objective of a back-propagation network is to find the weight that approximate target values of output with a selected accuracy. The least-mean square error method, along with the generalized-delta rule, is used to optimize the network weights in back-propagation networks. The sigmoid and hyperbolic-tangent functions are the most commonly used continuous-transfer functions in the back-propagation networks. After the output of the neuron is transmitted to the next layer as an input, this procedure is repeated until the output layer is reached. The error between the output of the network and the target outputs are computed at the end of each forward pass. If an 
error is higher than a selected value, the procedure continues with a reverse pass; otherwise, training is stopped. In the reverse pass, the weights in the network are modified by using the error value.

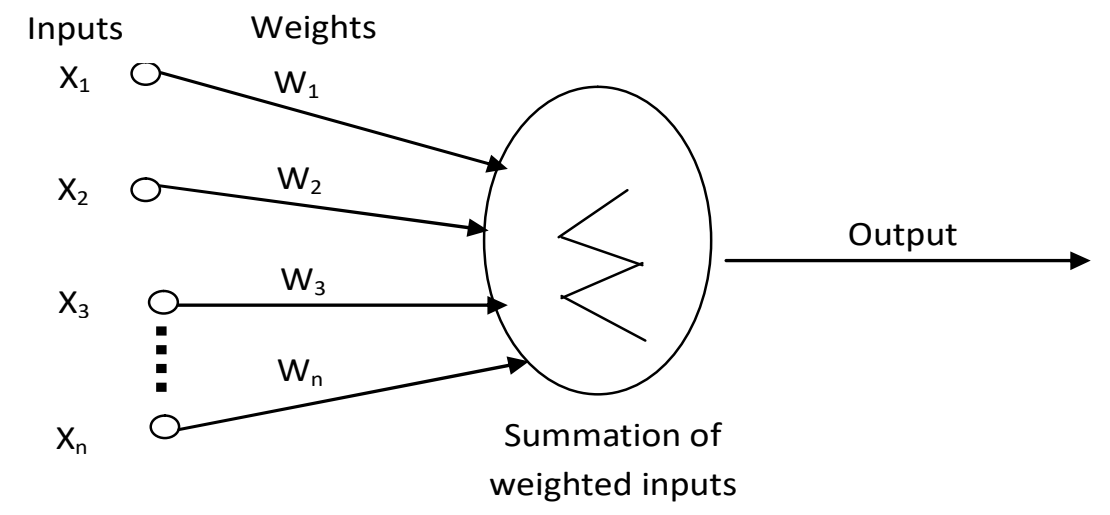

Figure 2: Structure of a network

\section{Methodology}

The daily rainfall data of all the raingauge stations in the catchment area, the daily records of water levels with corresponding capacities and various outflows made from the reservoirs have been collected from the Office of Water Resources Department, Dhamtari, Govt. of Chhattisgarh. There are seven raingauge stations in catchment area of the Ravishankar Sagar Reservoir. Average monthly rainfall for this catchment has been computed using the thiessen weight for each of the seven raingauge. Thiessen weight has been computed by constructing the thiessen polygon for the catchment. Monthly net inflow has been computed by the available records of the levels capacity and out flow from reservoir for the periods 1979 to 2007. The relationship between rainfall and inflow is quite complex and is nonlinear in nature. Artificial neural network (ANN) is one the technique suited to problems that are mathematically difficult to describe. Many studies have proved that ANNs are capable of performing quite satisfactorily in rainfall-runoff modeling. In this paper a monthly rainfall-inflow model for Sondur Reservoir has been developed using ANN technique. Sondur river is a monsoon fed river hence model has been developed for June to October month.

A three layer feedforward back propagation neural network (BPNN) model has been constructed to simulate the rainfall and inflow. The monthly rainfall has been taken in input layer and monthly inflow has been taken in output layer. One hidden layer has been taken. There is one node (neuron) in input and output layers. Several trials have been tried with different number of nodes in hidden layer and the performance of each model have been tested by computing the root mean square error (RMSE) for each model. The model with least value of RMSE will be the best model. The ANN toolbox available with the MATLAB package has been used for developing the model.

For ANN model development $80 \%$ data have been used for calibration and $20 \%$ data have been used for validation. The ASCE Task Committee reported that ANNs are not very capable at extrapolation. Thus care was taken to have the training data include the highest as well as the lowest values.

The RMSE value of the best ANN model with the number of node in hidden layer for different months has been shown in Table 1. The observed and estimated inflow by ANN model for the different reservoirs has been compared through Figures 3 to 7. 
Table 1. Performance characteristics of rainfall-inflow model

\begin{tabular}{|c|c|c|c|c|}
\hline \multirow[b]{2}{*}{ Reservoir } & \multirow[b]{2}{*}{ Month } & \multirow{2}{*}{$\begin{array}{l}\text { Number of } \\
\text { node in } \\
\text { hidden layer }\end{array}$} & \multicolumn{2}{|c|}{ RMSE Value } \\
\hline & & & $\begin{array}{c}\text { Training data } \\
\text { set }\end{array}$ & $\begin{array}{c}\text { Testing data } \\
\text { set }\end{array}$ \\
\hline \multirow{5}{*}{ Sondur Reservoir } & June & 5 & 0.57 & 0.63 \\
\hline & July & 5 & 3.43 & 4.22 \\
\hline & August & 16 & 10.23 & 6.58 \\
\hline & September & 4 & 4.28 & 4.77 \\
\hline & October & 6 & 1.86 & 1.08 \\
\hline
\end{tabular}
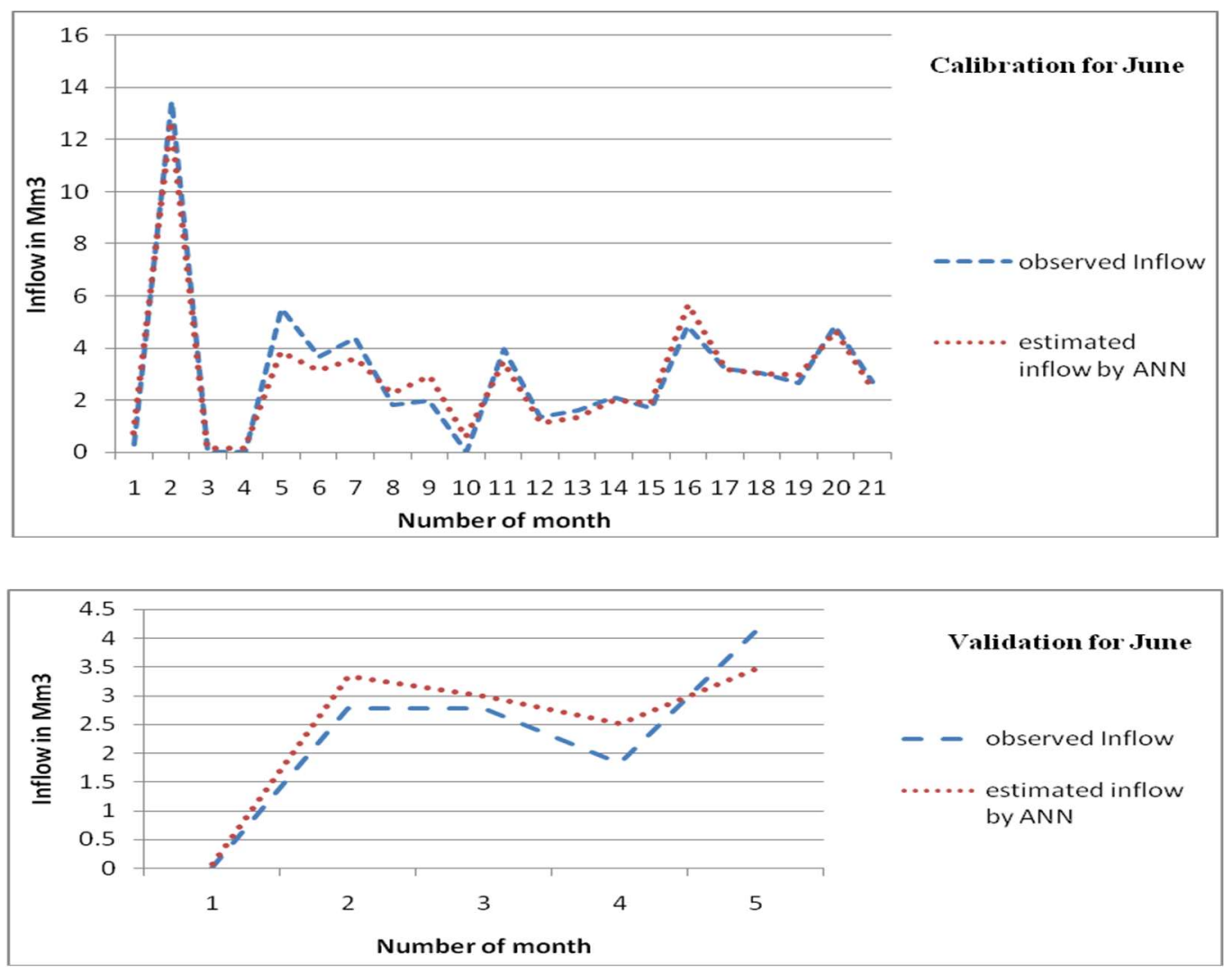

Fig. 3: Performance Comparison of observed inflow and estimated inflow by ANN model for Sondur Reservoir for the month of June 

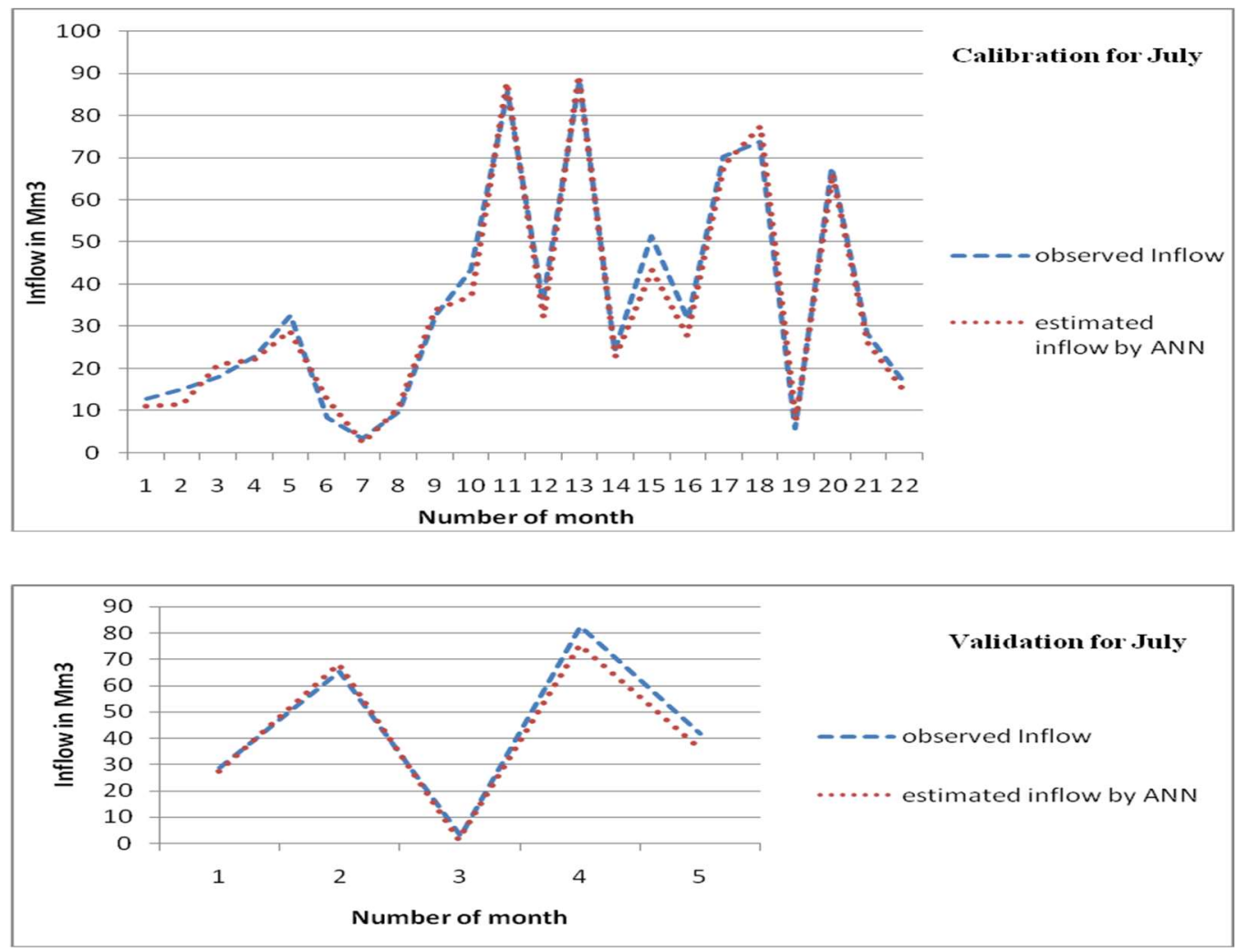

Fig. 4: Performance Comparison of observed inflow and estimated inflow by ANN model for Sondur Reservoir for the month of July
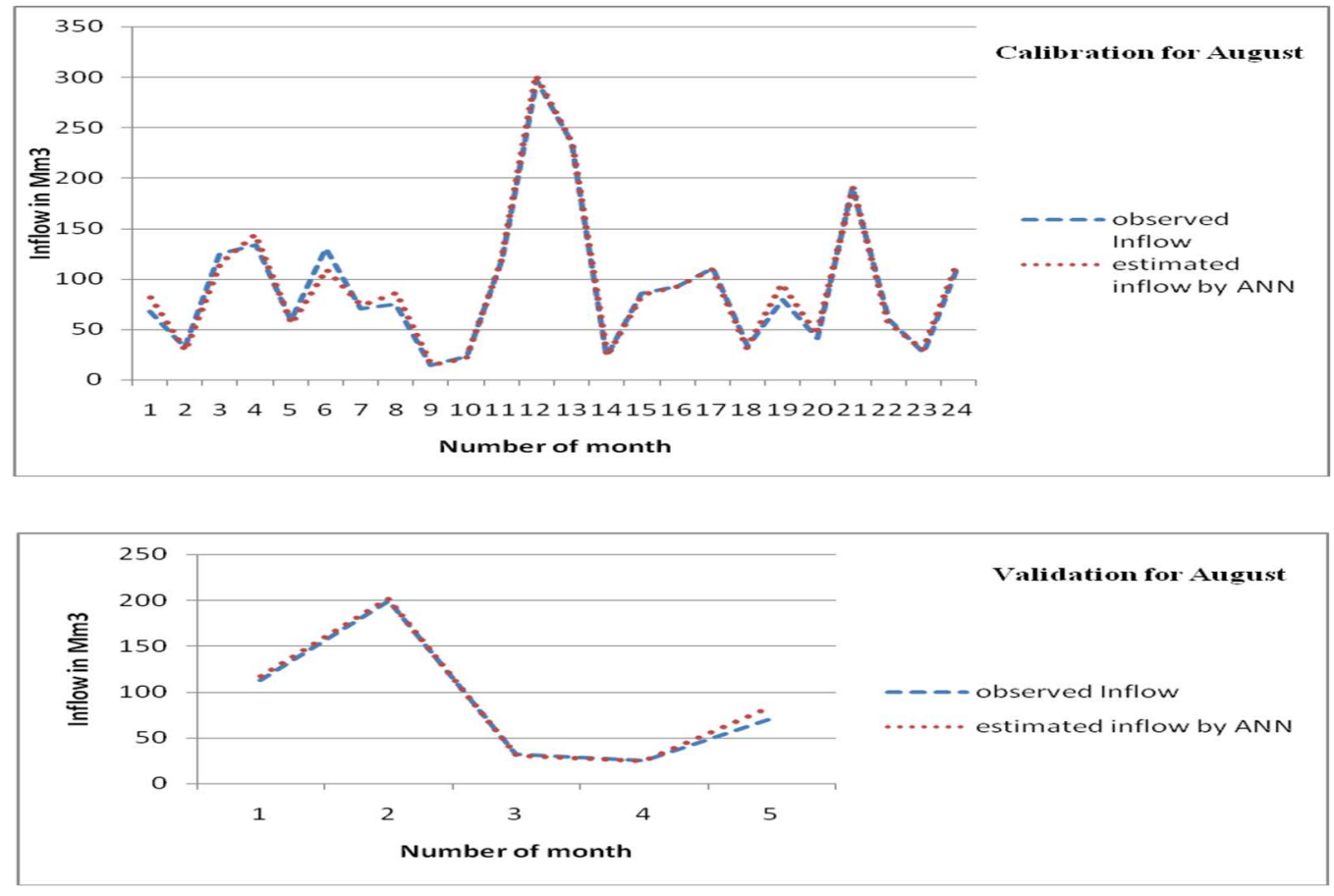

Fig. 5: Performance Comparison of observed inflow and estimated inflow by ANN model for Sondur Reservoir for the month of August 

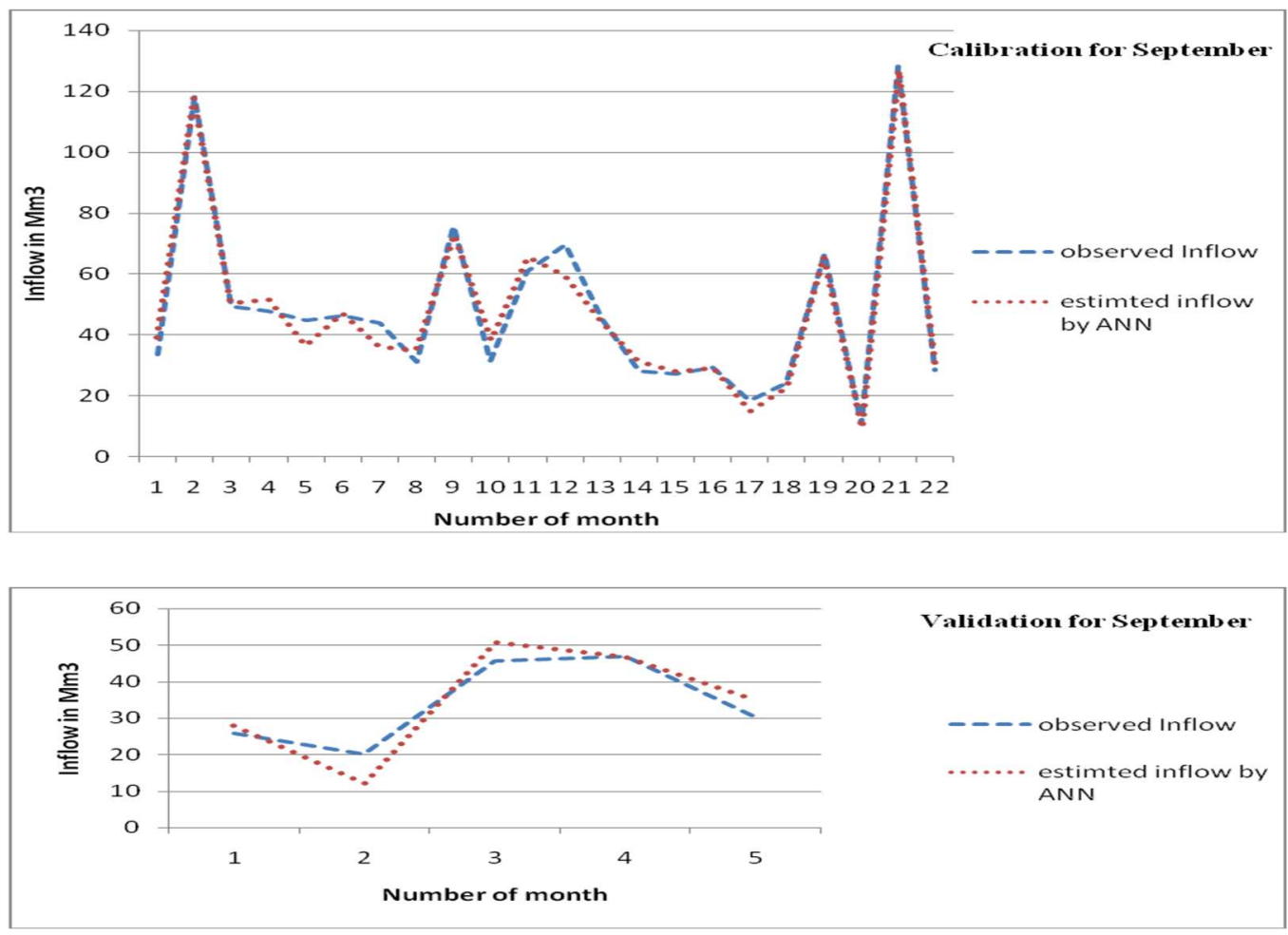

Fig. 6: Performance Comparison of observed inflow and estimated inflow by ANN model for Sondur Reservoir for the month of September
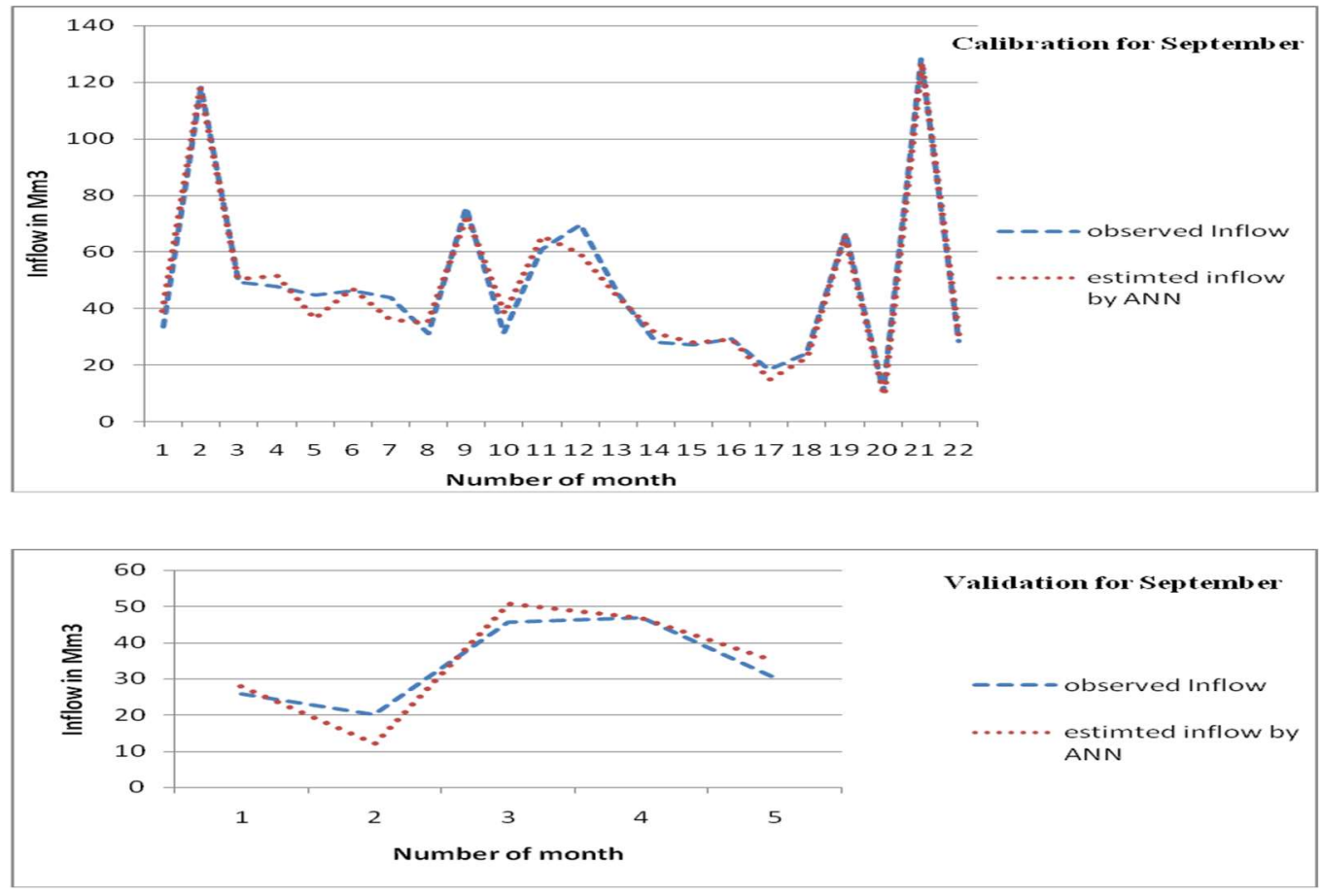

Fig. 7: Performance Comparison of observed inflow and estimated inflow by ANN model for Sondur Reservoir for the month of October 


\section{Conclusion}

The ANN model is useful tool to handle complex problems compared with other traditional model. The ANN model to simulate the monthly rainfall and inflow for monsoon months for the Sondur Reservoir has been constructed in this paper. To get the best model for different month several models have been tried with different number of neurons in the hidden layer. To test the performance of the model the RMSE value has been computed for each model. The model having least value of RMSE is considered as the best model. The number of neurons for the best model and the corresponding RMSE for different months has been shown in table-1. By the observation of the Fig. 3 to Fig. 7 it is clear that the calculated values of inflow by ANN model are very close to observed values of inflow. Hence the performance of the ANN model is good for rainfall-inflow simulation.

\section{References}

[1] C. W. Dawson, and R. Wilby, "An artificial neural network approach to rainfall runoff modeling", Hydrological Sci., Vol. 43(1), pp 47-66, (1998).

[2] S. K. Jain, A. Das, D.K. Srivastava, “Application of ANN for Reservoir Inflow Prediction and Operation”, Journal of Water Resources Planning and Management, Vol. 125, No. 5, pp 263-271, (1999).

[3] S. A. Tokar, and P. A. Johnson,,"rainfall-runoff modeling using artificial neural networks” J. Hydrol. Eng., Vol. 4, No. 3, pp 232-239, (1999).

[4] ASCE Task Committee on Artificial Neural Networks in Hydrology, "Artificial Neural Network in Hydrology II: Hydrologic Application”, Journal of Hydrology Engineering, Vol.5, No.2, pp124-137, (2000b).

[5] S. A. Tokar, and M. Markus,"Precipitation-runoff modeling using artificial neural networks and conceptual models", J. Hydrol. Eng., Vol. 5, No. 2, pp 156-161, (2000).

[6] M. P. Rajurkar, U. C. Kothyari, and U. C. Chaube, "Artificial neural networks for daily rainfall-runoff modeling”, Hydrol. Sci. Journal, Vol. 47, No. 6 pp 865-877, (2002).

[7] Gokman Tayfur, and Vijay P. Singh, "ANN and Fuzzy Logic models for Simulating Event-Based RainfallRunoff”, Journal of Hydrology Engineering, Vol.132, No.12, pp1321-1330, (2006).

[8] Karim Solaimani, "Rainfall-runoff Prediction Based on Artificial Neural Network", American-Eurasian J. Agric. \& Environ. Sci., 5(6), pp 856-865, (2009).

[9] M. K. Verma and R. K. Shrivastav "Rainfall-Net Inflow Modelling for For Mahanadi Reservoir Project complex", Journal of Indian Water Resources Society, Vol. 20, No. 1, pp 27-34, (2000). 